\title{
Preventing Male Mental Illness in Post-war Britain
}

\author{
Ali Haggett
}

\section{INTRODUCTION}

Writing in 1960, Alfred Torrie, consultant psychiatrist and former superintendent of the Retreat at York, observed that many books had been written about the problems of children and old people; however, little guidance was available to middle-aged men with personal problems. Having identified this lacuna in health advice literature, he noted that there were a number of reasons for such inattention:

The middle-aged man is expected to have reached maturity; to be in the prime of life; to have passed the problems of adaptation to adulthood; to have become settled; to have become a husband and a father; and to be respected in the community as a leader, looked up to by his fellows. ${ }^{1}$

${ }^{1}$ Alfred Torrie, The Middle Aged Man: The Way of Understanding (London: The Church of England Moral Welfare Council, 1960), 2. Torrie was medical director of the National Association for Mental Health after the Second World War, and was also associated with the Tavistock Clinic, the Child Guidance Movement and the National Marriage Guidance Council.
A. Haggett $(\bowtie)$
Centre for Medical History, University of Exeter, Exeter, UK
e-mail: A.N.Haggett@exeter.ac.uk
(C) The Author(s) 2019
D. Kritsotaki et al. (eds.), Preventing Mental Illness, Mental Health in Historical Perspective, https://doi.org/10.1007/978-3-319-98699-9_12 
It was understandable, therefore, that 'he is passed by as someone who is perfectly able to manage himself and his affairs'. In his advice pamphlet, Torrie went on to warn that men were not always so invincible, but in fact, they could be prone to a host of 'stress diseases' such as: gastric ulcers, coronary heart disease, high blood pressure and other intestinal disorders. Because these conditions were 'physical' in presentation, he warned 'the fact that the middle age man is unhappy and suffering from emotional disability is often passed by'. Touching on a number of important challenges of 'middle age', he drew attention to the fact that men might increasingly become prone to hypochondriacal illness, weight gain and anxiety about the loss of looks and sexual potency. Disappointment and depression were the likely result, according to Torrie, when men attempted to 'hitch [their] wagon to a star in middle age'. ${ }^{2}$

Not only was this pamphlet indeed one of a very small number of publications aimed specifically at men's health and well-being, it is questionable how widely it was read-or how useful it was, given that Torrie's recommendations were that, for such men, the ultimate solution was spiritual, involving nothing less than complete commitment to God. ${ }^{3}$ The lack of preventive health information available to men in the decades following the Second World War is the focus of this chapter. As a number of scholars have begun to show, men's psychological problems have historically been less visible, perhaps because it has more usually been the male 'gaze' that has observed and examined-the male norm being that by which others have been measured. ${ }^{4}$ In part, as a result of the enduring cultural association between women and irrationality, many assumptions have been made about gender and health through the decades. In previous work, I have shown how male distress has tended to

${ }^{2}$ Ibid., 2, 5. For a history of stress, see Mark Jackson, The Age of Stress: Science and the Search for Stability (Oxford: Oxford University Press, 2013).

${ }^{3}$ Torrie, The Middle Aged Man, 15.

${ }^{4}$ Ali Haggett, A History of Male Psychological Disorders in Britain, 1945-1980 (Basingstoke: Palgrave Macmillan, 2015), 18. See also Mark Micale, Hysterical Men: The Hidden History of Male Nervous Illness (Cambridge, MA: Harvard University Press, 2008), 281; and Steve Robertson and Robert Williams, "Men, Public Health and Health Promotion: Towards a Critically Structural and Embodied Understanding," in Men, Masculinities and Health, eds. Brendan Gough and Steve Roberson (Basingstoke: Palgrave Macmillan, 2009), 61. 
present 'atypically', in ways that do not fit comfortably within the current clinical paradigm for mental illness. ${ }^{5}$ It is also now increasingly accepted that men are less likely to recognise poor psychological health, and reluctant to seek medical help when they do. ${ }^{6}$ As Torrie noted pertinently in 1960, many men were terrified of consulting the medical profession for help, in fear that they might be told their unhappiness was due to mental disorder. ${ }^{7}$ This chapter seeks to extend the boundaries of previous work, to explore the discourse around gender and prevention of mental illness in Britain from the 1950s. How was important information about health and well-being communicated to men? What were contemporary concerns about psychological health? How did men conceptualise good mental health, and to what extent was there demand for preventive information? Drawing on a range of printed primary material, archival material from the National Association for Mental Health (NAMH/MIND) and studies of health information and lay medicine, the chapter will explore the medical, political and cultural context within which men and women negotiated ideas about their own well-being. It will argue that, for a range of complex reasons and competing exigencies, male mental health was almost entirely neglected-both reflecting and reinforcing prevailing assumptions about masculinity, coping and the image of the 'strong, silent man'.

\section{New Anxieties, and Communicating Health in Post-war BRITAIN}

It is now well documented that during the twentieth century, the West witnessed a decline in infectious disease and a rise in what has variously been described as 'chronic' diseases such as cardiovascular disease, cancer and diabetes. Historians have viewed this epidemiological transition in different ways and cautioned that chronic illness has a long history

\footnotetext{
${ }^{5}$ Haggett, A History of Male Psychological Disorders, Chapter 1.

${ }^{6}$ See, for example, Anne Cleary, "Suicidal Action, Emotional Expression and the Performance of Masculinities," Social Science and Medicine 74 (2012): 498-505; David Wilkins, Untold Problems: A Review of the Essential Issues in the Mental Health of Men and Boys (London: Men's Health Forum, 2010); Roger Kingerlee, Duncan Precious, Luke Sullivan, and John Barry, "Engaging with the Emotional Lives of Men," The Psychologist 27, no. 6 (2014): 418-21.

${ }^{7}$ Torrie, The Middle Aged Man, 10.
} 
that precedes the twentieth century. ${ }^{8}$ David Armstrong suggests that the statistics do not reflect a simple biological reality, but in fact illustrate how medicine began to reconfigure the natural ageing process of decay and degeneration, to a pathological process to be diagnosed and treated..$^{9}$ Nevertheless, it is certainly the case that during the 1960s, concerns were raised about conditions, which could conceivably be 'preventable' if lifestyles were moderated or changed. The importance of prevention and the role of social factors in disease were at the heart of theories put forward by the social medicine movement in Britain, which, although it remained peripheral to clinical medicine, nonetheless attempted to bridge the divide between prevention and cure. ${ }^{10}$ Not only did the apparent rise in numbers of non-communicable diseases cause clinical concerns, but the fiscal pressures of health and welfare provision prompted urgent debates about public health policy-with particular reference to smoking, diet and alcohol consumption. As Virginia Berridge has noted in her extensive work on public health policy, concerns about smoking and lung cancer during the 1950s marked the change of emphasis from acute infectious to chronic disease 'and the beginnings of a new lifestyle-oriented, activist, single-issue public health, which came to fruition in the 1970s'. ${ }^{11}$ Increasingly, in this new era of public health, the government assumed responsibility for advising the public on health matters, by utilising the most up-to-date mass media. At the heart of these developments was the concept of population level, 'risk-factor' medicine, associated strongly with the Scottish epidemiologist Jerry Morris, who argued that 'individuals had considerable influence over their own health and needed to utilise self-reliance and self-control'. ${ }^{12}$

${ }^{8}$ See Carsten Timmermann, "Chronic Illness and Disease History," in The Oxford Handbook of the History of Medicine, ed. Mark Jackson (Oxford: Oxford University Press, 2011), 2, https://doi.org/10.1093/oxfordhb/9780199546497.013.0022.

${ }^{9}$ David Armstrong, "Chronic Illness: A Revisionist Account," Sociology of Health and Illness 36, no. 1 (2014): 15-27.

${ }^{10}$ Dorothy Porter, "Introduction," in Changing Disciplines, ed. John A. Ryle (New Brunswick, NJ: Transaction, 1994 edition), xxxi. See also George Weisz, Chronic Disease in the Twentieth Century: A History (Baltimore: John Hopkins University Press, 2014).

${ }^{11}$ Virginia Berridge, Marketing Health: Smoking and the Discourse of Public Health in Britain, 1945-2000 (Oxford: Oxford University Press, 2007), 2.

${ }^{12}$ Weisz, Chronic Disease, 191. See also Virginia Berridge, "Smoking and the New Health Education in Britain, 1950s-1970s," American Journal of Public Health 95, no. 6 (2005): 956-63. 
For a number of reasons, however, communicating these new concerns to the public was not straightforward. In the 1950s, the medical profession was subject to established ethical conventions, which prevented advertising and discouraged contact with the media. Clinicians, more broadly, were also notoriously suspicious of media publicity. ${ }^{13}$ As numerous historians have noted, a culture of secrecy surrounded the medical profession-deference and moral authority provided a means by which they distanced themselves from quacks who advertised patent medicines as consumer goods. ${ }^{14}$ One consequence of this was that patients knew very little about their illnesses. As Alex Mold has shown, 'a culture of paternalism existed within the medical profession, perpetuating the view that "the doctor knows best" and patients should accept a largely passive role'. ${ }^{15}$ Doctors believed that informed patients were dangerous and that media coverage of medical issues would result in anxiety and hypochondria. ${ }^{16}$ The limited range of broadcast material on BBC radio was, as Ayesha Nathoo notes, paternalistic, with 'the BBC prescribing the types of programmes listeners should hear, and doctors entrusted with deciding what was best for their patients' ${ }^{17}$ However, during the 1960s, this situation began to change, heralded by the growth of post-war social surveys and the emergence of early patient advocacy groups, which demonstrated that patients wanted more information about health and disease. ${ }^{18}$

The government agency central to health information during the late 1960s was the Health Education Council (HEC), set up in 1968 and reformed in 1973. ${ }^{19}$ The Royal College of Physicians' 1962 report

${ }^{13}$ Kelly Loughlin, "Networks of Mass Communication: Reporting Science, Health and Medicine in the 1950s and 1960s," in Making Health Policy: Networks in Research and Policy After 1945, ed. Virginia Berridge (Amsterdam and New York: Rodopi, 2005), 303-4.

${ }^{14}$ Virginia Berridge, "Smoking and the Sea Change in Public Health, 1945-2007," Policy Paper, History and Policy, 4 June 2007.

${ }^{15}$ Alex Mold, Making the Patient Consumer: Patient Organisations and Health Consumerism in Britain (Manchester: Manchester University Press, 2015), 18.

${ }^{16}$ Anne Karpf, Doctoring the Media: The Reporting of Health and Medicine (London: Routledge, 1988), 4.

${ }^{17}$ Ayesha Nathoo, Hearts Exposed: Transplants and the Media in 1960s Britain (Basingstoke: Palgrave Macmillan, 2009), 37.

${ }^{18}$ See Mold, Making the Patient, Chapter 1.

${ }^{19}$ Berridge, "Smoking and the Sea Change." Prior to the Second World War, the ministry supported voluntary organisations, such as the Central Council for Health Education, but moved to centralise services during the War to deal with national exigencies. 
on smoking and the 1964 report of the Cohen committee on health education highlighted the need for central publicity on health issues, promoting a 'new breed' of educators, trained in journalism and behavioural sciences. ${ }^{20}$ Through the 1970s, the HEC employed advertising agencies to produce posters, brochures and newspaper adverts highlighting the dangers of smoking. ${ }^{21}$ From the 1950s, the Central Office of Information (COI), which was formed after the War and the closure of the Ministry of Information, continued a much longer history of transmitting public information films on aspects of public safety and health. ${ }^{22}$ Concurrently, as other historians have noted, television broadcasting began to cover medical topics, both fictionally and in documentary style. ITV's Emergency Ward 10 (1957) and the BBC's pioneering series, Your Life in their Hands (1959) both attracted large audiences. Despite continued tensions about the dangers of well-informed patients, both were generally well received. ${ }^{23}$ It is within this context that this chapter will turn next to explore the ways in which shifting patterns of disease and new models of communication impacted upon preventive health information directed at men.

\section{Lay Medicine and Discourses of Health}

From the rich archive of public information films produced by the COI, material on psychological well-being — and most specifically advice directed to men-is notable by its absence. From post-war austerity to Thatcher's privatisation during the 1980s, themes reflected the social, cultural, political and scientific context of the time. Similarly, medical topics reflected anxieties about health-related exigencies. In the immediate post-war period, films emphasised the importance of preventing the spread of cold and cough viruses. The dangers of drink driving were highlighted during the 1960s, and the risks associated with smoking

${ }^{20}$ Ibid.

${ }^{21}$ Ibid., 960-61.

${ }^{22}$ See Timothy Boon, "Films and the Contestation of Public Health in Interwar Britain" (Ph.D. diss., University of London, 1999).

${ }^{23}$ See Michael Essex-Lopresti, "Your Life in Their Hands," Lancet 368 (2006), s24s25; Kelly Loughlin, “'Your Life in Their Hands': The Context of a Medical-Media Controversy," Media History 6, no. 2 (2000): 177-88; and Nathoo, Hearts Exposed, 46. 
during the 1970s. ${ }^{24}$ Many of the public information films focused on safety risks associated with the failure to wear car safety belts, irresponsible use of fireworks and the dangers of railway tracks and electric power stations. ${ }^{25}$ The government response to the emergence of the AIDS virus is now well documented, and roundly portrayed in the 1980s media campaign, chillingly entitled 'Don't die of Ignorance'.

Although topics appeared to circumvent themes on psychological well-being, one darkly comedic film, entitled What a Life, released by the COI in 1949, perhaps gave some insight into the pressures of being a man in post-war Britain. The film featured two businessmen, worn down by austerity, who together, attempt to end their lives by drowning. Their suicide plots fail, and the film ends with the men returning to the bar for last orders, laughing uncontrollably at their plight. The film was attacked in the House of Commons for its doom-mongering. A Conservative MP wanted to know if it had been an appropriate way to spend $£ 9000$ of taxpayers' money. ${ }^{26}$ It is perhaps ironic that the film explicitly embraced the theme of male misery and distress; yet, government information campaigns never fully pursued this topic, nor implemented preventive strategies to foster positive mental health and well-being.

Not only did campaigns focus on a set of medical priorities, mostly unrelated to psychological health, in many cases, they highlighted health risks to women and not to men. As Berridge has noted, during the late 1950s, when the connection between smoking and lung cancer became clear, the medical profession and the Ministry of Health had major anxieties about directing health education towards men, who were the largest group of smokers at that time. Women re-emerged in the 1970s in anti-smoking campaigns as mothers, with the smoking problem defined in accordance with their reproductive rolealthough the 'at-risk' foetus in adverts was usually portrayed as male. ${ }^{27}$ Unsurprisingly, concerns about the overuse of alcohol also reflected long-established moralistic overtones about women and alcohol, despite

\footnotetext{
${ }^{24}$ Berridge, "Smoking and the New Health Education," 959.

${ }^{25}$ Films available at http://www.nationalarchives.gov.uk/films/.

${ }^{26}$ See BFI Screenonline, http://www.screenonline.org.uk/film/id/1120964/index. html, last accessed 11 February 2018.

${ }^{27}$ Berridge, "Smoking and the New Health Education," 961-62.
} 
the fact that drinking alcohol has been one of the most common ways in which men have self-medicated for distress-and alcohol-related morbidity/mortality has historically been much greater in men. As historians have shown, the focus has commonly been 'not so much on women as women, but on women as mothers, and on the notion of maternal neglect'. ${ }^{28}$ Information available to the public was also often 'female-focused'. A literature review of health information published as recently as 1994 found many studies on specific conditions that affect women, such as the menopause. Other research focused upon 'women's preferences' in relation to other diseases. ${ }^{29}$ Elaine Kempson, who published a well-cited review of consumer health information in 1987, held discussion groups with people 'likely to have needed health information in the recent past'. Notably, among this group were 'wives of men recovering from surgery'. Implicit in the design of the study, therefore, was the assumption that women were more likely than men to seek health information. Local studies appeared to support this contention, and Kempson noted that 'women, traditionally, bear the responsibility for the health and care, not only of their children, but also of sick and elderly relatives'. ${ }^{30}$

In 1973, C.P. Elliot Binns, a general practitioner from Northampton, published a paper in the Journal of the Royal College of General Practitioners, which gave some insight into the social and cultural factors around advice-seeking behaviour. Based on a survey of his patients, Elliot Binns confirmed that 'in the past, medical care has been the prerogative of women, and it apparently still is'. Male relatives, he noted, when

${ }^{28}$ Peter Borsay, "Binge Drinking and Moral Panics, Historical Parallels?," History and Policy, http://www.historyandpolicy.org/policy-papers/papers/binge-drinking-and-moral-panics-historical-parallels, last accessed 20 April 2018. See also Virginia Berridge, Rachel Herring, and Betsy Thom, "Binge-Drinking: A Confused Concept and Its Contemporary History," Social History of Medicine 22, no. 3 (2009): 597-607.

${ }^{29}$ Sarah Buckland, "Unmet Needs for Health Information: A Literature Review," Health Libraries Review 11 (1994): 82-95 (84 and 86).

${ }^{30}$ Elaine Kempson, Informing Health Consumers: A Review of Health Information, Needs and Services (London: College of Health, British Library, 1987), 6 and 50. For a historical perspective on women as medical consumers, see Ali Haggett, Desperate Housewives, Neuroses and the Domestic Environment, 1945-1970 (London: Pickering and Chatto, 2012), 153; and Nancy Tomes, "Skeletons in the Medicine Closet: Women and 'Rational Consumption' in the Inter-war American Home," in Health and the Modern Home, ed. Mark Jackson (New York: Routledge, 2007), 177-95. 
approached to give medical advice, tended simply 'to suggest a visit to the doctor', and it was 'most unusual for a male patient to receive advice from someone of his own sex'. Typifying the attitude of many male patients, Elliot Binns described the case of a middle-aged man, recently widowed, who came to his surgery complaining of backache. The man had 'consulted no one, because he had no friends' and had bemoaned: 'anyway, if I got some ointment, there's no one to rub it in'. The survey suggested that, although a doctor's advice was considered to be the most reliable, impersonal sources of medical information were increasingly important. Women's magazines, 'home doctor books' and the use of home remedies illustrated that home medical care played an essential role. ${ }^{31}$ A repeat survey, published in 1986, found very little change, except that pharmacists and the television emerged as increasingly popular sources of information. ${ }^{32}$ A 1960 study of medicine consumption suggested that, from adolescence, pharmacological consumption began to decline in boys, but rose in girls. The rise continued significantly, until after age forty-five, when the gap between the proportion of men and women taking medicines-both prescribed and otherwise-began to narrow. The study also found that women took more laxatives and aspirin than men, and further that smaller families, who had higher levels of education, were more likely to be prescribed medication. ${ }^{33}$

If home doctor books and media advice were popular, they merely served to reinforce the assumption that women should be responsible for home health-and that men did not need instruction in such things. It is difficult to gauge which books were consulted most frequently since specific titles did not appear in surveys. However, one notable publication, authored by Kenneth C. Hutchin, a former Major in the Royal Army Medical Corps and general practitioner in Hatfield, deserves special attention. The book, entitled How Not to Kill Your Husband, published in 1962, was widely circulated and translated into six foreign languages. Hutchin, who authored the series anonymously as 'A Family Doctor',

${ }^{31}$ C.P. Elliot Binns, "An Analysis of Lay Medicine," Journal of the Royal College of General Practitioners 23 (1973): 255-64 (258, 262 and 264).

${ }^{32}$ C.P. Elliot Binns, “An Analysis of Lay Medicine: Fifteen Years Later," Journal of the Royal College of General Practitioners 36 (1986): 542-44.

${ }^{33}$ Margot Jefferys, J.H.F. Brotherston, and Ann Cartwright, "Consumption of Medicines on a Working Class Housing Estate," British Journal of Preventive and Social Medicine 14, no. 2 (1960): 64-76. 
appeared to agree with Alfred Torrie, that men were more vulnerable than most would assume. Chapter 1 of his book opened unequivocally: 'That many men manage to survive the forties is largely a matter of luck. Very few men could claim any credit for this achievement'. Expanding further, Hutchin confirmed that his book was explicitly 'addressed to women', since, 'when it comes to looking after their health, many men are complete imbeciles. The lucky ones are the ones who have wives who will do it for them'. Acknowledging that some men might find such attention stifling and feel as though they were 'tied to their wives' apron strings', he cautioned that 'it is better to live a long time at the end of your wife's apron strings, than to be completely free, and dead'. ${ }^{34}$ The book proceeds to explore a wide range of physical conditions, with particular focus on the heart, the arteries and coronary thrombosis-but notably with nothing dedicated directly to psychological well-being. Hutchin did observe that some men were prone to what he described as 'gastric neurosis', caused by stress and often by over-consumption of medicines from the bathroom cupboard. Gastric pain, he noted, was more likely to be in the mind than the stomach. Advising the reader that wives should take their husbands for a holiday to the sea, taking all the medicines in the bathroom cupboard with them in an old suitcase: 'When they arrive, they can go down to the end of the pier and drop the whole thing into the sea' ${ }^{35}$ The author did concede that prevention was better than cure and that 'over stress, over smoking, over eating, over working and over drinking' were excesses that might result in a major calamity such as a coronary thrombosis. ${ }^{36}$ Nevertheless, the overall message from Hutchin merely reinforced the stereotypical view of the strong, silent man. Stating that it was 'better' for a wife to take control of the situation, he noted that 'the man who fusses about his health can never be normal, because it is not normal for a man to fuss about his health'. ${ }^{37}$ Hutchin ended his book with a word of caution to women. In addition to keeping a watchful eye over her husband's health, she should also remain 'fun' and ensure that her personality remain a source of attraction for him: 'The wife who allows her husband to live it up

\footnotetext{
${ }^{34}$ A Family Doctor, How Not to Kill Your Husband (London: George Allen and Unwin Ltd, 1962), 11-12.

${ }^{35}$ Ibid., 171.

${ }^{36}$ Ibid., 96.

${ }^{37}$ Ibid., 13.
} 
with his secretary or some model, is failing in her duty to him. It is not only a wife's duty to keep her husband alive, it is her duty to keep him'. Marriage could potentially be lethal, he warned, since 'wifing a husband is often far more effective than knifing him'. ${ }^{38}$

Hutchin went on to publish numerous other medical texts on a range of topics such as coughs, colds, hypertension and allergy. Presumably, testament to its success, the 'family doctor' series continued over the next decade with the titles: How Not to Kill Your Wife (1965), How Not to Kill Your Children (1968) and How Not to Kill Yourself (1973). Hutchin's text on wives, opens with a chapter entitled, 'Don't Kill your Goose', and the caveat: 'In writing this book, I realise that it will not have the same popular appeal as How Not to Kill Your Husband, for men have not the same vested interest in keeping their wives alive'. ${ }^{39}$ Through a series of chapters on such topics as calories, cigarettes and the 'sexwife' (in which men were reminded that sex in marriage was not only for their gratification), the book attempts to rebalance spousal responsibility for the family's health. Men are even reminded that wives should not be the 'family doormat'. However, it falls spectacularly into gendered assumptions about propensity towards specific diseases. Unsurprisingly, whole chapters are dedicated to hormones, menstruation and the menopause. Husbands are reminded that menstruation and the premenstrual period take up more than a quarter of a woman's life and therefore, 'the subject dominates your wife's thoughts'. However, Hutchin warns that 'it is a mistake to use any expression which implies that menstruation is an illness or a hardship - or any word which could make a girl feel sorry for herself' ${ }^{40}$ More striking is the fact that an entire chapter is dedicated to anxiety and psychological difficulties, a topic that was notably absent from his book on men. Reminding husbands that if sympathetic assurance or astringent firmness failed, severe cases might need to be attended to by an expert psychiatrist. The book closes leaving the reader in no doubt that a wife should be loved and cherished, but that women were more naturally fitted to caring for others-and at the same time predisposed to hormonal and psychological difficulties.

${ }^{38}$ Ibid., 216 and 223.

${ }^{39}$ A Family Doctor, How Not to Kill Your Wife (London: George Allen and Unwin, 1965), 9 .

${ }^{40}$ Ibid., 29 and 33. 
Writing again just a year later (this time under his real name), in a book entitled The Health of the Businessman, Hutchin dedicated a whole chapter to 'stress'. Replete with references to the working day, business life and coronary thrombosis, the material still provided little by way of helpful advice about psychological health. Preventive advice was limited to suggestions that the businessman should delegate more and avoid frustration. Indeed, should stress produce psychological or psychosomatic symptoms, guidance weighed heavily towards medical intervention. If stress reached acute levels minor tranquillisers-particularly those combined with antispasmodics and analgesics-were recommended for muscular and mental relaxation. ${ }^{41}$ As I have shown elsewhere, these 'combi-drugs' were widely prescribed to men through the 1960s and 1970s, but did not appear in statistics for gender and psychotropic drug prescriptions, in part distorting the degree to which women appeared more likely to receive psychotropic therapy. ${ }^{42}$

As medical topics increasingly gained exposure during the 1960s, 'control' over what topics were covered became ever more important. As Nathoo notes, 'the [medical] profession aimed to retain a low profile but a high status'. ${ }^{43}$ Nevertheless, the public increasingly desired more information about health and medicine. Men and women, for example, sought medical advice from agony columns in newspapers and magazines. Throughout the 1960s and 1970s, columns emerged in most of the well-read publications, and by the early 1980s, the well-known agony aunt Claire Rayner received 1000 letters a week, in addition to the audience reached via other work in broadcast television and radio. ${ }^{44}$ Richard Smith, then editor of the British Medical Journal, writing in 1983, noted that problem pages reached huge audiences in waiting rooms around the country. Medical advisor himself to a magazine, he observed that 'letters come from anxious women, whose cantankerous old fathers refuse to see a doctor [...] Letters do come from men, but I've never seen a letter from a man worried about his mother, wife or daughter, who would not see a doctor'. Letters to problem pages suggested that the public usually

\footnotetext{
${ }^{41}$ Kenneth C. Hutchin, The Health of the Businessman (London: Business Publications, 1966), 285.

${ }^{42}$ See Haggett, A History of Male Psychological Disorders, Chapter 4.

${ }^{43}$ Nathoo, Hearts Exposed, 42.

${ }^{44}$ Richard Smith, "Part Time Agony Aunt in Trousers," British Medical Journal, 8 October 1983, 1029-31.
} 
fell into two camps: those who had sought medical advice already, and those who had not - the latter being the most worrying. Often, people felt that they had received the 'wrong' advice; some claimed that they were victims of negligence, and others felt that their doctor was not interested in their problems. ${ }^{45}$ Despite this, general practice surveys of the time suggested that the public were broadly satisfied with primary care, but increasingly demanded more information. ${ }^{46}$

Alex Mold has shown in detail how, through the 1960s and 1970s, growing importance was attached to patient autonomy and consumerism in health care. A number of drivers were central to this-of note was the emergence of bioethics and notion of 'informed consent'. Within this context, patient advocacy groups began to emerge such as the Patients Association (1963), and later, the College of Health (1983). ${ }^{47}$ Given that patients' autonomy moved gradually away from a situation in which the medical profession had previously wielded such control, it is perhaps not surprising that patients' desire for information focused initially on medical exigencies - aspects of health and disease that were viewed as priority. Kempson, in a literature review of previous research, illustrated that patients wanted information about: specific illnesses; impending medical treatment; diagnostic tests, drugs and their side effects. ${ }^{48}$ Preventive advice-particularly that on mental health-did not feature strongly in the literature. Sarah Buckland's later study, published in 1994, stated specifically that all research had focused broadly on 'disease and coping' information. Patients' knowledge of health-related issues was still 'poor' and there was a lack of knowledge about where to seek information. ${ }^{49}$

Research indicated that there were a number of barriers to obtaining health information. Where patients consulted the family doctor, communication problems often arose during the consultation. ${ }^{50} \mathrm{~A}$ number of studies suggested that working-class patients tended to be diffident asking questions. Hence, those who had received a higher level of education

${ }^{45}$ Ibid., 1030.

${ }^{46}$ See Ann Cartwright, Patients and Their Doctors: A Study of General Practice (London: Routledge and Kegan Paul, 1967); and Mold, Making the Patient Consumer, 18.

${ }^{47}$ See Mold, Making the Patient Consumer, Chapters 1 and 5.

${ }^{48}$ Kempson, Informing Health Consumers, 19 and 52.

${ }^{49}$ Buckland, "Unmet Needs for Health Information," 86.

${ }^{50}$ For a history of communication in general practice, see Haggett, A History of Male Psychological Disorders, Chapter 1. 
and were more assertive in their approach received more information. ${ }^{51}$ Specifically, patients who were more emotionally expressive received more information. Men were notoriously poor at showing their emotions, in particular with regard to seeking medical advice. ${ }^{52}$ As recently as the 1980s, scholars from the social sciences argued that physicians' 'need for power' continued to influence their practice when giving information. This was exacerbated if patients had only known their physician for a short time. ${ }^{53}$ Elliot Binn's 1973 study of lay medicine demonstrated that patients felt advice on psychiatric illness was poor in comparison to that on physical illness. Further, he found that those with psychiatric disorders often postponed a visit to the doctor. Informal sources of advice were often untrustworthy, sometimes causing unwarranted or excessive anxiety - and nurses, perhaps surprisingly, scored particularly high when it came to 'frightening the patient'. Home doctor books were often kept long after they were out of date. One respondent claimed to have used a work by Aristotle, which had apparently been 'instrumental in saving five lives'. Even recent books, cautioned Binns, might be misleading. ${ }^{54}$ Although, as Mold illustrates, by the 1980s, health-related topics were frequently covered in magazines such as Which, surveys suggested that the public was still poorly informed. ${ }^{5}$ Medical books in public libraries were frequently out of date and doctors expressed concern that articles in newspapers and magazines left people 'half informed'. ${ }^{56}$ By the late 1980s, the Consumer Association and the associated Which? Group had begun to produce information on health topics that aligned with a preventive approach; Mold notes that the audience for such material was not inconsiderable. ${ }^{57}$ However, given the long-standing trend in which

${ }^{51}$ Howard Waitzkin, "Information Giving in Medical Care," Journal of Health and Social Behavior 26, no. 2 (1985): 81-101 and 83; and Richard L. Street Jr., "Information Giving in Medical Consultations: The Influence of Patients' Communicative Styles and Personal Characteristics," Social Science and Medicine 32, no. 5 (1991): 541-48 (541).

${ }^{52}$ See Haggett, A History of Male Psychological Disorders.

${ }^{53}$ Waitzkin, "Information Giving," 84.

${ }^{54}$ Elliot Binns, "An Analysis of Lay Medicine" (1973), 261-63.

${ }^{55}$ See Mold, Making the Patient Consumer, 122; and Buckland, "Unmet Needs for Health Information," 86.

${ }^{56}$ Kempson, Informing Health Consumers, 33 and 35.

${ }^{57}$ Mold, Making the Patient Consumer, 122. Mold suggests that the Which? Way to Health publication had 65,000 subscribers by 1993 . See 122 . 
women appeared more comfortable seeking health-related guidance and information, the degree to which men were beneficiaries is questionable.

\section{Mental Health Organisations and Discourse on Gender}

As patients made the gradual move towards greater autonomy and informed choice, parallel developments emerged in the third sector as organisations concerned with mental illness and mental handicap gained visibility. The National Association for Mental Health was established in 1946, by merging three separate organisations previously focused on mental health, mental handicap and child psychiatry: The National Council for Mental Hygiene (established in 1922); the Central Association for Mental Welfare (established in 1913); and the Child Guidance Council (established in 1927). The organisations merged during a period of great change: the development of the NHS and psychiatric services, alongside new drugs for the treatment of mental illness. The NAMH was founded on a set of objectives aimed at promoting greater understanding towards, and knowledge about, mental illness. It also emphasised the importance of treatment and training. Drawing on themes that were central to the Council for Mental Hygiene, the NAMH also sought to promote a greater understanding of the ways in which good mental health could be achieved and sustained, thereby, in many ways espousing a preventive approach. As Jonathan Toms notes, in 1970, the NAMH began a national campaign, which aimed to raise the profile of mental illness. It increasingly adopted the role of a pressure group, changing its name to MIND in $1973 .{ }^{58}$ Although its remit was broadly to lobby in support of 'patients' who were already experiencing mental illness (and increasingly their families), their role in educating the general public about mental health and illness remained important. A review of the organisation's archival material from the 1960s reveals much about discourses of prevention-particularly with regard to gender.

During the 1970s, MIND recognised the importance of educating young people about mental health and the organisation produced school teachers' 'kits' with advice on how teaching staff should approach the subject. Packs consisted of useful colour-coded sheets allowing teachers

\footnotetext{
${ }^{58}$ Jonathan Toms, "Mind the Gap: MIND, the Mental Hygiene Movement and the Trapdoor in Measurements of Intellect," Journal of Intellectual Disability Research 54, no. 1 (2010): 16-27 and 16.
} 
not only to impart information to students, but also to design interactive sessions with them. Notes for teachers on the healthy development of adolescents synthesised theories from contemporary psychology: transactional analysis, gestalt theory and humanistic psychology—all of which emphasised a holistic approach. ${ }^{59}$ Throughout the material, the importance of a stable family environment is underlined. Information sheets for children were very detailed and attempted a balanced perspective, attaching broadly equal importance to psychological and physical approaches to treatment. However, the material reflected many gendered assumptions about mental illness, suggesting that women were a discreet category, explicitly more prone to mental illness. ${ }^{60}$ Posters featuring images of children suggested that 'one child in eight will need mental hospital treatment at some time'-five girls and three boys appear on the poster. Case studies included fictitious accounts such as that of 'Mrs A', the 'careful housewife and loving mother, who became irritable, anxious and depressed', and 'Mrs B', who suffered from agoraphobia and 'has agreed to see a psychiatrist'. Schizophrenic cases were usually depicted as male-as were alcoholics. ${ }^{61}$ An action sheet, designed to 'stimulate discussion about our own feelings and our bodies' suggested that students read a book by Katherina Dalton, entitled The Menstrual Cycle (1969). An excerpt was included:

During the premenstrual period, women are more prone to have accidents, to make mistakes, to commit suicide and to be admitted to psychiatric units. Studies of schoolgirls have shown that marks are much lower during their premenstrual periods, exam results are lower and that discipline problems increase. Women teachers are more likely to give lower marks or to discipline during their own premenstrual periods. ${ }^{62}$

Another action sheet that encouraged students to think about the connections between mind and body, asked girls to keep a record of how they felt physically and mentally during 'several cycles'. Boys were simply

\footnotetext{
${ }^{59}$ Wellcome Archives and Manuscripts (hereafter Wellcome), SA/MIN/B/109, Schools, “Teachers' Packs".

${ }^{60}$ Wellcome, SA/MIN/B/109, Schools, Teachers' Kit, "What is Mental Illness?"

${ }^{61}$ Wellcome, SA/MIN/B/109, Schools, Teachers' Kit, "Poster" and "Case Studies."

${ }^{62}$ Wellcome SA/MIN/B/109, Schools, Teachers' Kit, "Action Sheet 1.”
} 
asked to record how they felt at different times of the day. ${ }^{63}$ It is difficult to know how widely these packs were circulated in schools. Prior to the introduction of the National Curriculum in 1988, head teachers and governors determined curriculum content and much variation existed between schools. However, any student participating in activities with these resources would be left in no doubt that concerns about mental well-being were likely to be of greater concern to girls and women than to boys and men.

During the 1970s and 1980s, NAMH and MIND published numerous books and pamphlets on women's mental health. The organisation stated explicitly: 'It is our view that insufficient time and attention are devoted to the consideration of women's mental health needs. Throughout society, the interests of men dominate, and this is reflected in the mental health field'. ${ }^{64}$ Such claims must be seen within the context of feminist campaigns that justifiably moved to highlight women's concerns on two levels. Firstly, feminist commentators argued that the roots of much mental illness in women could be traced to anger, frustration and oppression-'symptoms' of existing in a patriarchal society. The corollary of this was that tranquillisers were widely assumed to have been overprescribed for disorders 'caused by the social system'. ${ }^{65}$ Secondly, serious cases of professional misconduct and abuse against women emerged from within medicine and psychiatry itself, gaining widespread attention and criticism from advocacy groups. Indeed, MIND's material is replete with references to poorly managed mixedsex psychiatric wards; inappropriate sexual contact between therapists and patients; domestic violence; the impact of declining mental health services; and racism in psychiatry against women from ethnic minorities. ${ }^{66}$

A MIND campaign, 'Stress on Women', later in 1992, lobbied for women-only spaces on psychiatric wards, new policies to tackle sexual

${ }^{63}$ Wellcome, SA/MIN/B/109, Schools, Teachers' Kit, "Action Sheet 3."

${ }^{64}$ Women in Mind (London: Mind, 1985), 2; Wellcome, SA/MIN/B/131, "Women."

${ }^{65}$ Claims set out in Women in Mind, 7 and 8. See also Haggett, Desperate Housewives.

${ }^{66}$ For example, Mind Information Leaflet, "Women and Mental Health Services: Some Are More Equal Than Others," c. 1987; Mind Information Leaflet, "Women Sexually Abused by Their Therapists," c. late 1980s. 
harassment and an independent advocacy to assist users in speaking out. ${ }^{67}$ Given such alarming claims of subjugation and abuse, it is perhaps not difficult to appreciate the level of anger and emotion surrounding these debates. One regular contributor to MIND publications, Janet Gorman, roundly reflected the views of many in a pamphlet entitled, Stress on Women, Out of the Shadows (1992). In this scathing account of inequality, she noted that women were disadvantaged in a range of medical, legal and social arenas. Referring to the 'men's movement' in the United States, Gorman bemoaned:

The American men's movement guru Robert Bly, contends that men have gone 'soft' and has been attempting to save yoghurt-eaters and turn them into wild men, through workshops and weekend retreats, where men can find their masculine selves, beat drums and rediscover the beast within.

However, Gorman cautioned that it was women who still feared crime and sexual violence. ${ }^{68}$ Medically, socially and culturally then, the discourse surrounding poor mental health and the prevention of mental illness centred upon the unmet needs of women. These needs were embraced firmly by the feminist movement and other advocacy groups, such as MIND, that campaigned to challenge abuse and discrimination.

There was nonetheless one arena in which there were genuine opportunities for the needs of men to take centre stage. During the post-war period, the workplace increasingly became the focus of political and medical debate about occupational health. During the 1960s, driven by concerns about sickness absence and absenteeism, the topic attracted much attention, not only politically, but also among industrialists and psychologists. The broader history of workplace health and safety

${ }^{67}$ Katherine Darton, Janet Gorman, and Liz Sayce, Eve Fights Back: The Successes of MIND's Stress on Women Campaign (London: MIND, 1994), 24; Wellcome, SA/ MIN/B/131, "Women."

${ }^{68}$ Janet Gorman, Stress on Women, Out of the Shadows, MIND Campaigns for Women's Mental Health (London: MIND, 1992), 9 and 10. During the 1970s, concerns about the negative aspects of the male role led to a 'men's liberation' movement in the United States. A small collective of men in London also began producing a magazine called Achilles Heel, which aimed to challenge traditional forms of masculinity. However, the movement was less influential in the UK than in the United States. See Joseph Pleck and Jack Sawyer, eds., Men and Masculinity (Englewood Cliffs, NJ: Prenice Hall, 1974); Victor J. Seidler, The Achilles Heel Reader: Men, Sexual Politics and Socialism (London: Routledge 1991); and Haggett, A History of Male Psychological Disorders, 8. 
has been well covered and is not the focus of this chapter. ${ }^{69}$ However, during the 1970s and 1980s, the NAMH/MIND became actively involved in promoting the importance of the mental health of workers. Their attempts to influence policy demonstrate how challenging it was to engage political support for a preventive, holistic model of workers' health.

The NAMH submitted evidence to the Committee on Health and Safety at Work, which was appointed in 1970 and chaired by Labour politician and trade-unionist, Lord Alfred Robens. The Committee reported in 1972, and the recommendations were largely enacted in the Health and Safety Act, 1974. As I have shown elsewhere, the recommendations from the Robens Report fundamentally changed the principles of workplace health and safety, as emphasis shifted increasingly towards self-regulation and voluntary codes of practice. The new legislation clearly placed the responsibility for workplace welfare on employers and employees. ${ }^{70}$ The NAMH appointed a working party of industrialists and medical officers to investigate mental health at work and submit a set of recommendations to Robens. In their report, they identified common psychological symptoms as a serious cause of absence from work, noting that if cases of psychosomatic illness were included in the data, 'certified absences due to mental ill-health, ha[d] increased more than any other form of illness'. ${ }^{71}$ The data reflected earlier patterns in occupational health, suggesting that levels of psychoneurosis in women were rising; however, men featured more regularly in diagnoses for headache, dyspepsia and a range of other ill-defined illnesses. As the NAMH noted, such conditions were increasingly recognised as symptoms of 'stress'. ${ }^{72}$ Among their recommendations, the working party stated that members of industrial health services should be fully trained in mental health and that an occupational health service should be established as a requirement within the National Health Service. They also advocated further

${ }^{69}$ See Vicky Long, The Rise and Fall of the Healthy Factory: The Politics of Industrial Health in Britain 1914-60 (Basingstoke: Palgrave Macmillan, 2011); Arthur J. McIvor, A History of Work in Britain, 1880-1950 (Basingstoke: Palgrave Macmillan, 2001); and Paul Weindling, ed., The Social History of Occupational Health (London: Croom Helm, 1985).

${ }^{70}$ Haggett, A History of Male Psychological Disorders, 59.

${ }^{71}$ Wellcome, SA/MIN/B/43, Employment, "Evidence for Submission to the Committee on Safety and Health at Work," ND c. 1971.

${ }^{72}$ For more detailed discussion of men, work and psychosomatic disorders during the 1940s, 1950s and 1960s, see Haggett, A History of Male Psychological Disorders. 
research into the relationship between mental health/mental illness and employment. ${ }^{73}$ The NAMH recommendations were formally articulated in a MIND Report, published in 1971, which stated that many managers in industry were 'ignorant of mental ill-health and its treatment'; that many doctors were 'ignorant of the working life of their patients'; and that the annual reports of the factory inspectorate gave "no indication that any research at all [was] being undertaken by the department into the mental health aspects of employment' ${ }^{74}$ They also pointed out that symptoms of stress and poor mental health were not limited to executives and were found in workers of all levels of responsibility. The report advised that prevention of mental illness could be achieved by awareness of four key 'danger points' in the workplace: over-promotion, underwork, ill-defined job descriptions and poor consultation and communication by management. ${ }^{75}$ The Robens Report, when it was formally published in 1972, fell far short of these recommendations-in particular, the proposal that an occupational health service should be established in parallel with the National Health Service. The NAMH expressed deep disappointment with the findings, stating that it had 'singularly overlooked the factors necessary for the promotion and maintenance of mental and social wellbeing, as opposed to physical health and safety'. Reaffirming the weaknesses of existing legislation, the NAMH protested that laws applied 'almost entirely to the physical aspects of manual work $[\ldots]$ paying little or no regard to the mental health of employees'. It warned further that there was 'reason to fear that the operation of the [occupational health] service will reflect the Department of Employment's traditional concern with industrial diseases, hygiene and safety, at the expense of mental health'. ${ }^{76}$

A NAMH symposium on the topic of Management and the Working Environment, held later in 1972, exposed the political tensions at the core of debates about employment and health. Alan Fisher, General Secretary of the National Union of Public Employees, argued that the Government needed to be proactive on a range of levels with regard to both physical and psychological health-points, he noted, that had

\footnotetext{
${ }^{73}$ Wellcome, SA/MIN/B/43, Employment, "Evidence for Submission to the Committee on Safety and Health at Work," ND c. 1971.

${ }^{74}$ Wellcome, SA/MIN/B/121, Stress, "MIND Report Stress at Work," 2.

${ }^{75}$ Wellcome, SA/MIN/B/121, Stress, "MIND Report Stress at Work," 2-3.

${ }^{76}$ Wellcome, SA/MIN/B/121, Stress (response to Roben's Report).
} 
been articulated clearly to the Robens Report. However, Christopher Chataway, Conservative Minister for Industrial Development, disagreed, responding that the Government should occupy a 'supporting role', and that the primary responsibility for health lay with 'those who create the risks and those who work with them'. Indicating a degree of scepticism on the matter, Chataway cautioned that stress at work was a relatively unexplored field, 'in which it [was] very easy to make facile generalisations about the incidence of mental illness and its supposed cause'. Ultimately, without wishing to dispense with legislative control altogether, the Government's position was that streamlining and rationalisation of occupational health were possible-'self-help', in their view, was the key to further progress. ${ }^{77} \mathrm{~A}$ medical model of intervention therefore prevailed in occupational health, underplaying the importance of the psychosocial environment and prevention of poor mental health at work. Interest in men's mental health more broadly, was overshadowed by a set of competing priorities: anxieties about the population's physical health and the rise of chronic disease; and publicity about women's psychological needs and their treatment by psychiatric profession.

\section{Conclusion}

At a one-day conference on 'The Health of Business Executives', convened by the Chest and Heart Association in 1959, Sir Richard Powell, Director General of the Institute of Directors, delivered a plenary paper. In his speech, he recounted to delegates a story about a research investigation into 'health problems' among the working population. One man had responded to the health questionnaire by 'scribbling' across the form: 'Never had a day's illness in my life and I never see a doctor'. All subsequent questions were left unanswered. A few weeks later, the research team received a letter from his executors, informing them of the man's death from thrombosis-requesting that his name be withdrawn from the study. This anecdote neatly reflected the way in which men were prone to indifference when it came to their own health, often rejecting the need for medical assessment or intervention. Although the conference claimed to promote a preventive approach to the health of executive men, emphasis remained on the physical risks of heart disease,

\footnotetext{
${ }^{77}$ Wellcome, SA/MIN/B/43, Employment, "Symposium, Management and the Working Environment," 1972.
} 
hypertension, overweight and lack of exercise. Even the paper on 'stress and responsibility' was couched in the language of hypertension and 'avoiding the coronary club'. ${ }^{78}$ By the late 1980 s, little had changed, although there was limited acceptance in some circles that the mind and emotions could impact on cardiac disease and other physical illness. One senior consultant cardiologist at Charing Cross Hospital in London, for example, diligently observed that most of his patients suffered 'not from an excess of fatty food, but from an internal disorder caused by struggling too hard with life for too long'. ${ }^{79}$

The model of masculinity that prevailed in the West undoubtedly emphasised stoicism and inscrutability, which impacted negatively on men's awareness of (and openness to) preventive measures in health and well-being. The notion that women were responsible for the health of their families further exacerbated the notion that it was not 'normal' for a man to take care of himself or to 'fuss' about his health. Although some psychologists and commentators in the United States and Britain raised concerns about the negative aspects of the male role, it is not clear that they influenced the lives of ordinary men in any significant way. ${ }^{80}$ Moreover, the ways in which women faced a host of serious challenges, politically, socially and medically were increasingly made visible, bolstered by the feminist movement, which gradually extended its agenda beyond the boundaries of 'equality' to matters of medicine and psychiatry. Within this context, the notion that men might be vulnerable to anything other than coronary heart disease would invariably have been viewed as politically and socially insensitive.

The stigma attached to mental illness was also particularly challenging for men, who were reluctant to admit to vulnerability and 'not coping'. Investigations into discrimination in the workplace indicated widespread prejudice against workers who declared a history of mental illness. A MIND pamphlet on the topic, published in 1978, exposed numerous examples of job applications that were either rejected or rescinded and promotions that were blocked by employers. General practitioners were understandably reluctant to declare psychological disorders on sickness certificates.

\footnotetext{
${ }^{78}$ The Chest and Heart Association, The Health of Business Executives: Transactions of a One-Day Conference Held in the Royal Festival Hall, London, November 1959 (London: Chest and Heart Association, 1960), 10 and 19.

${ }^{79}$ Wellcome, SA/MIN/B/107, Mental Health Statistics 1975-93, pamphlet c. late 1980s. ${ }^{80}$ Haggett, A History of Male Psychological Disorders, 8.
} 
Diagnoses suggestive of neuroses were often vague, or a more acceptable symptomatic diagnosis would be given on the certificate. ${ }^{81}$ More broadly, as this chapter has shown, although the model of public health in Britain increasingly moved towards lifestyle-oriented, preventive measures, the focus was largely on targeted physical health: cancer, heart disease, smoking, overweight and diabetes. ${ }^{82}$ In this milieu, poor mental health in menarguably less visible and less well understood-was overlooked.

There is much to contemplate from this historical perspective. In twenty-first-century Britain, many cultural assumptions persist about gender and vulnerability to mental illness. While women are diagnosed with the most common mental disorders twice as often as men, the suicide rate in men is three times that in women. Recent concerted campaigns have done much to raise the profile of mental health and well-being more generally; however, as a number of scholars submit, there is now an 'empathy gap' and 'gender blindness' towards challenges faced by men. Violence and sexual misconduct-poor behaviour-exhibited by men is regarded as 'toxic masculinity' and questions are less likely to be asked about the social and emotional causes which invariably lead to 'damaged' men. Although there are a number of ways in which men are biologically and culturally vulnerable, it appears somehow inappropriate to highlight them. Serious attempts to challenge gender prejudice towards women have perhaps had the unintended consequence of 'reinforcing gender prejudice towards men'. ${ }^{83}$ Within the context of recent sexual abuses exposed by the Harvey Weinstein scandal and the \#MeToo movement, the notion that women are 'at risk' everywhere has become a powerful concept. ${ }^{84}$ While serious abuse must, of course, be taken seriously, the 'Weinstein moment' threatens to be divisive, propelling men and women (and scholarly interest) further in different directions. Within this climate, it seems likely that the mental health of men will remain poorly understood.

\footnotetext{
${ }^{81}$ David Ferguson, "A Study of Neurosis and Occupation," British Journal of Industrial Medicine 29 (1972): 420-31 (430).

${ }^{82}$ Berridge, Marketing Health, 2.

${ }^{83}$ Martin Seager, Warren Farrell, and John Barry, "The Male Gender Empathy Gap: Time for Psychology to Take Action," New Male Studies: An International Journal 5, no. 2 (2016): 6-16 (8).

${ }^{84}$ The 'Weinstein effect' or 'moment' refers to serious allegations of sexual misconduct, made in 2017, against the American film producer Harvey Weinstein. The allegations triggered a wave of similar accusations against men of other sectors. Subsequent campaigns have been described as a 'watershed moment' against sexual harassment of women.
} 
Open Access This chapter is licensed under the terms of the Creative Commons Attribution 4.0 International License (http://creativecommons.org/licenses/ by $/ 4.0 /$ ), which permits use, sharing, adaptation, distribution and reproduction in any medium or format, as long as you give appropriate credit to the original author(s) and the source, provide a link to the Creative Commons license and indicate if changes were made.

The images or other third party material in this chapter are included in the chapter's Creative Commons license, unless indicated otherwise in a credit line to the material. If material is not included in the chapter's Creative Commons license and your intended use is not permitted by statutory regulation or exceeds the permitted use, you will need to obtain permission directly from the copyright holder.

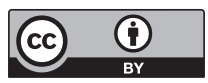

